Open Access

\title{
Chinese household consumption: how much is enough?
}

Qingwang Guo

\author{
Correspondence: \\ guoqw@ruc.edu.cn \\ China Financial Policy Research \\ Center, School of Finance Renmin \\ University of China, No.59 \\ Zhongguancun Street, Beijing \\ 100872, China
}

\begin{abstract}
Background: As per currently accepted methodology of national economic accounting, China's household consumption rate is considered relatively low. This paper discusses the evolvement of China's consumption over time.

Methods: Employing two different measures of consumption, I compare the growth rate of China's household consumption with the growth rates of China's economy, of its disposable income and of other nations' consumption.
\end{abstract}

Results: The results of the analysis demonstrate that China's household consumption is growing vigorously in terms of both real growth rates of per capita household consumption and in total retail sales of consumer goods.

Conclusions: Despite its current low level to GDP, China's household consumption has experienced a significant growth in recent years.

Keywords: Household consumption; Weak; Paradox

\section{至 Springer}

\section{Background}

According to the Expenditure Approach used in national economic accounting, the term "consumption" as used when calculating gross domestic product (GDP) refers to final consumption expenditures, including both household consumption expenditures and governmental consumption expenditures. Since governmental consumption expenditures usually account for only a relatively small proportion of GDP and are controlled by the government, it is mainly household consumption expenditure levels that have aroused concern. ${ }^{[1]}$

As per the currently accepted methodology of national economic accounting, China's household consumption rate is on the low side, ${ }^{[2]}$ as can be seen in Table 1 and Fig. 1. First, over the last 10 years, China's average household consumption rate was only $38.9 \%$, which is $35 \%$ lower than the average of upper-middle-income countries (59.4\%), less than half that of low-income countries (79.7\%), and $45 \%$ lower than lower- middle-income countries (70.3\%).

However, can we determine that China's household consumption is insufficient on this basis alone? No, we cannot. In addition to a few important socio-economic factors, there are still some other important indicators for determining whether household consumption is sufficient. Those include the real growth rate of household consumption expenditures and the real growth rate of total retail sales of consumer goods, among others.

(c) 2015 Guo. Open Access This article is distributed under the terms of the Creative Commons Attribution 4.0 International License (http://creativecommons.org/licenses/by/4.0/), which permits unrestricted use, distribution, and reproduction in any medium, provided you give appropriate credit to the original author(s) and the source, provide a link to the Creative Commons license, and indicate if changes were made. 
Table 1 Household consumption rates in China vs. other countries (\%)

\begin{tabular}{lcccc}
\hline & $1970-1980$ & $1981-1990$ & $1991-2000$ & $2001-2010$ \\
\hline Low-income countries, LIC & 80.3 & 80.8 & 81.3 & 79.7 \\
Lower-middle-income countries, LMIC & 69.0 & 69.6 & 71.0 & 70.3 \\
Upper-middle-income countries, UMIC & 62.8 & 60.7 & 62.3 & 59.4 \\
High-income countries, HIC & 57.2 & 56.5 & 56.8 & 55.8 \\
China & 59.5 & 51.0 & 45.6 & 38.9 \\
\hline
\end{tabular}

Source: calculations of relevant data as derived from the UN National Accounts Main Aggregates Database

\section{Methods}

Real growth rate of household consumption expenditures

China's average real growth rate of household consumption expenditures over the past 40 years was $8.3 \%$. The rate reached a height of $10.9 \%$ in the 1980 s (see Fig. 2). China's real growth rate of household consumption expenditures has fallen over the last 20 years, to an average over that period of $8.6 \%$. The average over the last 10 years fell to $8 \%$.

The question to address right now is how to determine whether the level of China's household consumption is high or low. This paper addresses that question from three points of view, namely, comparisons with the economic growth rate, comparisons with the income growth rate, and comparisons with other nations.

\section{Results and discussion}

Over the last 40 years, China's real economic growth rate averaged $9.1 \%$ annually, only $0.8 \%$ higher than the real growth rate of household consumption expenditures. Thus, the growth of household consumption expenditures stayed in pace with the economic growth rate. In the 1980s after Reform and Opening Up, the economic growth rate was $9.3 \%$, while the real growth rate of household consumption expenditures was $10.9 \%$. The real growth rate of household consumption expenditures (9.2\%) in the 1990s was 1.3 percentage points lower than the economic growth rate $(10.5 \%)$, while the real growth rate of household consumption expenditures $(8 \%)$ over the last 10 years was 2.5 percentage points lower than the economic growth rate $(10.5 \%)$. It should be pointed out that the gap between the real growth rate of household consumption

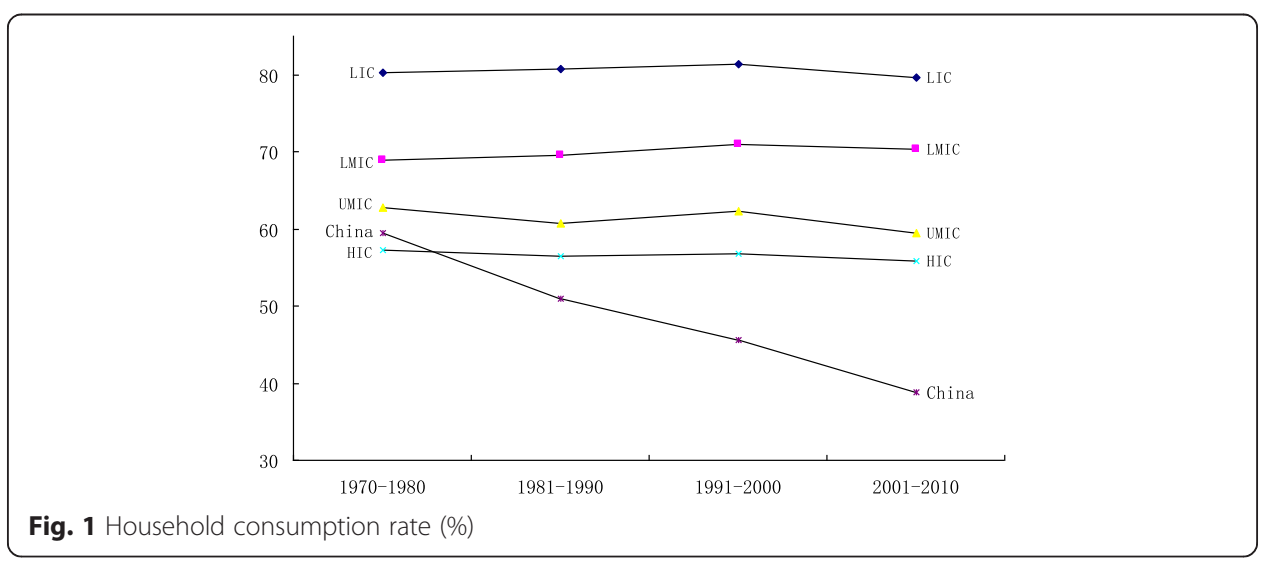




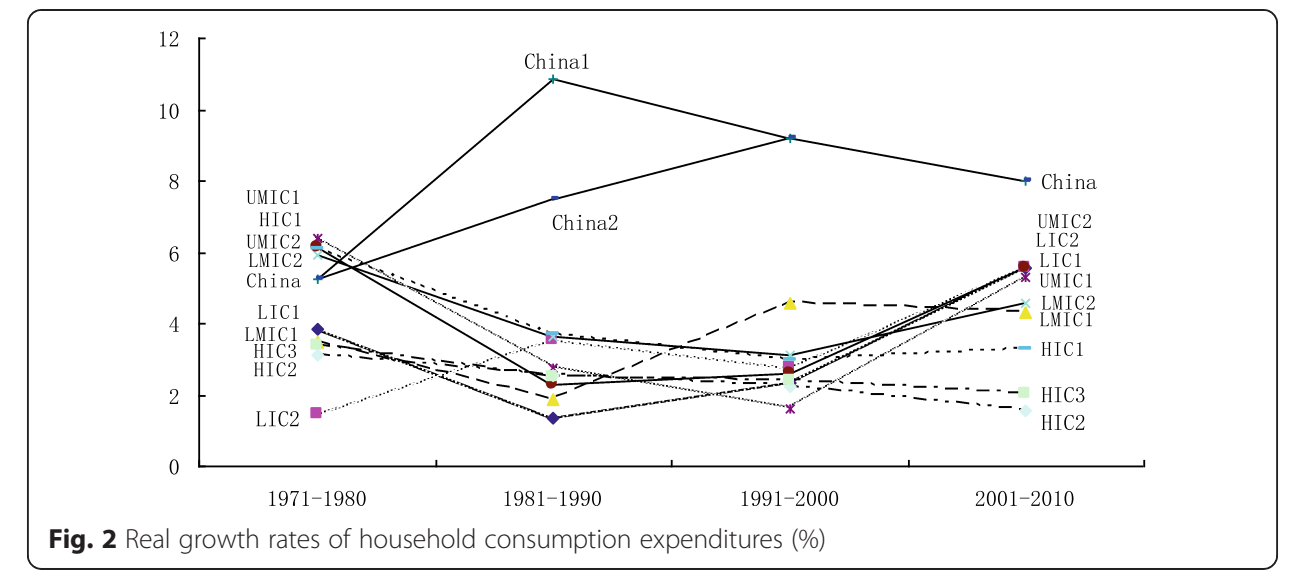

expenditures and the economic growth rate has increased in the last 20 years, but on this basis alone, it is not possible to determine that household expenditures are insufficient. Since the establishment of the socialist market economy in China, it has become necessary to establish a new social security system, a new housing system, and a new education system. All of these changes have prompted Chinese citizens to increase savings out of precaution. The growth rate of the economy has also continued to grow. All of these are the inevitable results of reform.

Over the past 30 years, the real growth rate of per capita disposable income of urban and rural households in China averaged $7.3 \%$, with urban households at $7.5 \%$ and rural households at $7.1 \%$. Over the same period, the real growth rate of per capita consumption of urban and rural households in China averaged $6.4 \%$, of which urban households averaged $6.7 \%$ while rural households averaged $6.1 \%$. The growth rates of per capita disposable income over the period stayed roughly in pace with the consumption level of urban and rural households. In particular, as shown in Fig. 3, in rural areas, per capita consumption levels grew almost exactly in step with per capita income levels.

The average growth rate of the 90 countries analyzed in this paper over the last 40, 30, 20 , and 10 years was $3.5,3.2,3.5$, and $4.2 \%$, respectively. In China, those numbers were $8.3,9.4,8.6$, and $8 \%$, respectively. In terms of per capita GDP levels, those countries with a population over 5 million can be divided into 10 categories. The average growth rate of household consumption expenditures as shown in Fig. 2 demonstrates that each category can be further divided into four groups every period. In the 1970s, the average growth rate of household consumption expenditures ranged from $1.5 \%$ within low-income countries (2) for the lowest group to $6.4 \%$ of upper-middle-income countries (1) of the highest group. China ranked in the lowest position among the group of countries with the highest growth rate, with an average growth rate of household consumption expenditures of $5.3 \%$. In the 30 subsequent years, China's average growth rate of household consumption expenditures far exceeded the rest. It reached $10.9 \%$ in the 1980s, $9.2 \%$ in the 1990 s, and $8 \%$ in the first 10 years of this millennium. That is three times higher than the highest category of high-income countries (1), twice as high as lower-middle-income countries (1), and 1.44 times higher than upper-middle-income countries (2). However, China's average growth rate of per capita household consumption expenditures was more prominent (see Fig. 4). It reached $9.2 \%$ in the 1980 s, $8.1 \%$ in the 1990 s, and $7.4 \%$ in the first 


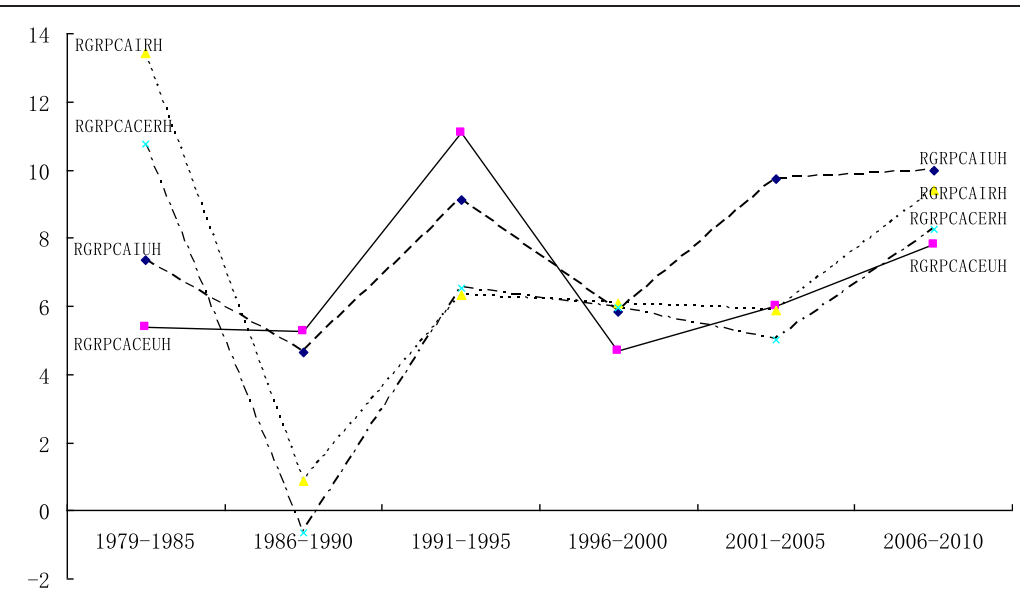

Fig. 3 Real growth rates of household consumption expenditures

10 years of this millennium, four times that of the highest category of countries within high-income countries (1), 3.8 times that of high-income countries (1), and 1.7 times that of upper-middle-income countries (1). In addition, excluding the extraordinary growth rates between 1981 and 1990, peaking at 44.4 \% in 1984. (see the curve "China 2" in Fig. 2), the growth rate of China's household consumption expenditures remained relatively stable as compared to other countries. Although the growth rate slowed down after the 1990s, at no point did the growth rate go negative.

\section{Real growth rate of total retail sales of consumer goods}

The Main Statistical Indicators section of the China Statistical Yearbook defines "total retail sales of consumer goods" as the amount of non-productive or non-operating physical commodities sold by enterprises directly to individuals and social groups, as

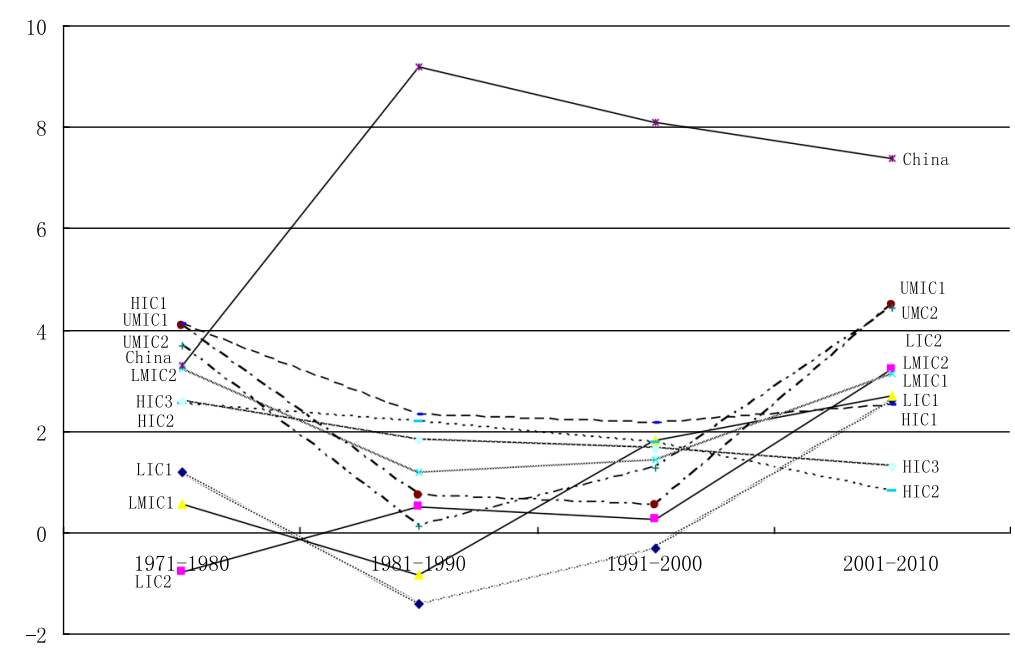

Fig. 4 Real growth rates of per capita household consumption expenditures (\%) 


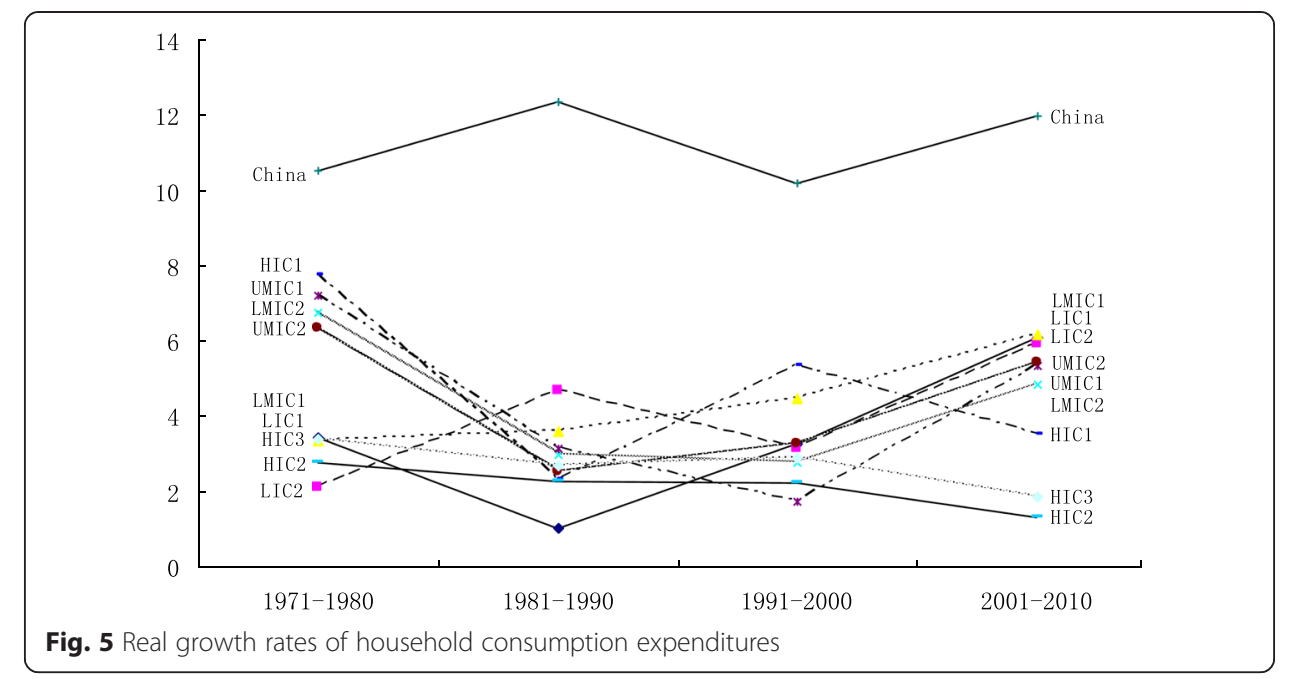

well as the amount of income gained through providing food and beverage services. This indicator can also be used to reflect the country's consumption level.

For the sake of comparability, we used UN National Accounts Statistics to analyze the real growth rate of the total retail sales of consumer goods in various countries. As shown in Fig. 5, China's real growth rate of total retail sales of consumer goods is much higher than that of other countries, as can be seen from the average over the past 40 years, in addition to other periods. Since Fig. 5 is similar to Fig. 2, here, we would like to supplement two brief points in the place of detailed analysis. First, Fig. 2 shows that China's growth rate of household consumption expenditures ranked the lowest among the group of countries with the highest growth rate in the 1970s, while Fig. 5 shows that China's real growth rate of total retail sales of consumer goods is much higher than that of other countries. Second, Fig. 5 demonstrates that China's growth rate of household consumption expenditures declined in the last 20 years, while Fig. 5 shows that China's real growth rate of total retail sales of consumer goods increased significantly in the last 10 years, despite declining in the1990s.

I have demonstrated through the above analysis that China's real growth rate of household consumption, real growth rate of per capita household consumption, and real growth rate of total retail sales of consumer goods all stand at high levels. So how high must the levels be before we can determine that China's household consumption levels are adequate?

\section{Remaining questions}

\section{The relationship between low consumption rates and high economic growth rates}

Some may ask why the consumption rate is so low while the real growth rate of household consumption expenditure is so high. One reason is China's relatively rapid economic growth rate. Although China's GDP has expanded quickly over the past 20 years, Chinese people's concepts, habits, and structures of consumption cannot be expected to change as rapidly in the short term. As a result, top marginal growth rate is driven by investment alone. Excluding net exports, it is estimated that the 
contribution rate of consumption to total economic growth is $65 \%$, and that investment makes up the other $35 \%$, leading to an ultimate economic growth rate of $7 \%$. If it is assumed that the economic growth rate will reach $10 \%$, the extra three percentage points inevitably require stimulation from increased investment. Thereafter, the contribution rate of investment will gradually increase. Adding one percentage point to total growth may require a $60 \%$ contribution rate of investment, while adding another percentage point on top of that may require a $70 \%$ contribution rate of investment. Adding a third percentage point may require as high as an 85 or $90 \%$ contribution rate of investment. Having already maintained a rapid economic growth rate for decades, China still kept up a growth rate of nearly $10 \%$ over the past 10 years despite two world economic crises. As this growth had to be driven by investment, it was inevitable for consumption rates to drop.

\section{Comprehensiveness of consumption data}

It is not uncommon for Chinese companies, government units, or even national authorities to issue shopping cards (vouchers) to their employees. These shopping cards are generally invoiced as office supplies, low-value consumables, etc., and their values are generally apportioned into the cost of production and operations or are recorded as office expenses or business expenses. However, employees use these shopping cards to buy daily necessities for personal use. This inevitably results in two problems. First, the value of the consumables which residents buy with their shopping cards cannot be included in the amount of consumption used to calculate the consumption rate, resulting in a reduced consumption rate. Second, residents can buy consumables without using their own existing income, resulting in the reduction of the household consumption expenditures. To a certain extent, this phenomenon can be used to explain why the household consumption rate is relatively low even as real growth rates of both household consumption expenditures and total retail sales of consumer goods are relatively high.

\section{Consumption structure}

The consumption structure mentioned in this paper refers to both the structure of consumables and the consumer structure.

By consumables, we refer to expenses such as food, clothing, household articles (including household appliances), accommodations, travel (including vehicles), and entertainment (including leisure tourism), almost all of which constitute household consumption expenditures in daily life. As income levels rise, the proportion of consumption expenditures of the former three areas will shrink, while that of the latter three areas will grow. However, many Chinese people today tend to spend their income to purchase real estate, which is viewed as an investment, while renting is viewed as consumption. Leisure tourism is becoming an increasingly important item within household consumption, but collective tours funded and organized by work units are still the norm.

The consumer structure can be broadly divided into three classes, namely lowincome consumers, middle-income consumers, and high-income consumers. Even though the marginal consumption tendency of low-income consumers is larger, their marginal contribution rate will be smaller due to their lower income level. The marginal contribution rate of the latter two classes to total household consumption is 
larger due to their higher income levels, even though their marginal consumption is less than that of the former. According to a report released by the World Luxury Association, as of the end of December 2011, the total annual consumption of luxury goods in China amounted to 12.6 billion US dollars (excluding private jets, yachts, and luxury cars), accounting for $28 \%$ of the global share. China has become the country with the largest consumption rate of luxury goods in the world. The global average household expenditure on luxury goods is $4 \%$ of household income. However, it is not uncommon for a Chinese household to spend $40 \%$ or more of household income to buy luxury goods. These groups are major drivers of the luxury goods market in China. ${ }^{(1)}$ The Chinese people's desire for consumption is red hot.

Both Chinese traditional culture and the current stage of China's economic development have a significant impact on domestic consumption demand. It would be too simplistic to say that consumption is weak in China.

\section{Safety concerns}

Some people may desire to consume certain products but are reluctant due to safety issues that have cropped up in food, clothing, and other daily use commodities. If basic safety requirements cannot be met, how can one expect people to spend money on products that may do them harm? The government tends to spend more energy managing the behaviors of producers and operators than it does to stimulate consumption.

These three problems will be mitigated as China's rate of urbanization increases, the dual economic structure is adjusted, an olive-shaped social structure forms, laws and regulations are solidified, and law enforcement and civic virtue are improved.

\section{Countermeasures against low consumption rates}

The government has rolled out a series of countermeasures in response to low consumption rates in recent years. They include increasing income levels, reforming the education and health care systems, improving the social security system, narrowing the income gap, etc. The implementation of these measures will enhance the potential spending power of the people, relieve widespread concerns, and free up more cash for immediate consumption. However, all these measures have been implemented with an eye to China's longterm development and long-term stability and are not simply intended to increase consumption. They are required to build a harmonious, stable, and affluent society. It will not be an overnight change. If these measures are implemented too quickly from the desire to drive up consumption, it is possible that the system will become distorted, and the government will ceaselessly run about putting out fires.

\section{Conclusions}

China's National Economic Accounting indicates that the Chinese consumption rate is on the low side. However, it is arbitrary to say that China's resident (household) consumption is insufficient or weak only based on this one indicator alone. This paper has attempted to make international comparisons on the basis of a large amount of sample data. The results demonstrate that China's household consumption is growing vigorously in terms of both real growth rates of household consumption and per capita household consumption and the growth rate of total retail sales of consumer goods. 
That being the case, why is China's consumption rate so low? Some purport that it is so low as a result of the high economic growth rate, in addition to the limited nature of data on consumption and other issues. If the economic growth rate fell to less than $7 \%$, the contribution rate of consumption to GDP and the percentage driven by consumption and final consumption expenditures to GDP would naturally increase significantly. However, if China's economic growth rate really slowed to less than $7 \%$, the resulting series of problems would be more serious than the current problems presented by a low consumption rate.

\section{Endnotes}

${ }^{[1]}$ According to the Explanation on the Main Statistical Indicators of the China Statistical Yearbook, household consumption expenditures refer to the total final consumption expenditures for goods and services of permanent resident households within a given period, including expenditures for goods and services paid directly with money, as well as goods and services provided to the employees by their employers in the form of payment, goods and services produced and consumed by households, and financial intermediation services provided by financial institutions.

${ }^{[2]}$ The household consumption rate, namely the final household consumption rate, means the proportion of the final household (resident) consumption expenditure within the GDP based on the Expenditure Approach.

Competing interests

The authors declare that they have no competing interests.

Author's information

Guo Qingwang is the Dean of the School of Finance of Renmin University of China. He is also the vice-president of China

Finance Society and China Tax Society. His research focuses on macroeconomic theory, financial theory, and policy.

\section{Submit your manuscript to a SpringerOpen ${ }^{\circ}$ journal and benefit from:}

- Convenient online submission

- Rigorous peer review

- Immediate publication on acceptance

- Open access: articles freely available online

- High visibility within the field

- Retaining the copyright to your article

Submit your next manuscript at $>$ springeropen.com 